\title{
CONTESTING MODERNITIES. PROJECTS OF MODERNISATION IN CHILE, 1964-2006
}

\author{
Gerard van der Ree, Dutch University Press, Amsterdam, 2007, 343 páginas. \\ Carlos Sanhueza $(*)$
}

El texto aquí reseñado corresponde a los resultados de una tesis doctoral presentada en el año 2007 en la Universidad de Leiden, Holanda. Su objetivo, tal y como lo declara el autor, se centra en explorar las maneras a partir de las cuales la élites políticas y económicas chilenas buscaron modernizar al país, en concordancia con su propia interpretación de la modernidad, así como los resultados de dichos impulsos modernizadores.

El texto se divide en seis capítulos más una introducción. En esta última se presentan los capítulos, como sus líneas centrales de discusión.

El primer capítulo se discuten algunos conceptos de modernidad y modernización a partir de los debates surgidos en Chile desde 1970. En este punto se destaca en qué sentido tales discusiones estuvieron más orientadas a lo político y lo práctico que a lo filosófico o teorético. Lo anterior, según el autor, viene a expresar el fuerte vínculo de los intelectuales chilenos con el mundo político. Estas relaciones las explica el autor dado el reclutamiento que hace el mundo político de la academia. Se analizan diferentes perspectivas de modernidad (barroca, socialdemócrata, liberal) así como su puesta en marcha y el papel de las élites en tal proceso de operacionalización.

En el segundo capítulo se aborda la construcción chilena de la modernidad, desde la época colonial hasta los años sesenta del siglo XX. Aquí se examinan determinadas formas de modernización empleadas, según el autor, generadas a partir de las heterogéneas posiciones de las elites.

(*) Académico del Instituto de Estudios Humanísticos Juan Ignacio Molina de la Universidad de Talca.

Correo electrónico: casanhueza@utalca.cl 
El tercer capítulo trata la "tercera vía" modernizadora: la revolución en libertad. El foco central está puesto en el estudio del gobierno de Eduardo Frei Montalva. Aquí se enfatiza la opción ideológica de la Democracia Cristiana, en tanto concitó una opción crítica de la modernidad, como también respecto de las estructuras políticas, económicas y sociales presentes en Chile.

El cuarto capítulo aborda la "vía chilena al socialismo y a la modernidad". Aquí el autor busca introducir, en el debate respecto de modernidad y modernización en Chile, una mirada al proyecto del gobierno de la Unidad Popular. En este aspecto, el autor afirma que, al centrarse la historiografía en el fenómeno rupturista que la Unidad Popular supuso, se ha descuidado aquellos elementos de continuidad que dicha experiencia política tuvo con los gobiernos anteriores.

El quinto capítulo aborda el modelo de modernización neoliberal implementado en Chile tras el Golpe Militar de 1973. Se analiza aquí la inspiración norteamericana (con Milton Friedman como figura clave), así como la forma de implementación del proyecto. Se destaca en qué sentido se aplicó un modelo externo, pero adaptado a la realidad nacional.

El último capítulo se centra en los gobiernos de la Concertación surgidos tras el retorno a la democracia. Al respecto, el autor destaca en qué sentido dichos gobiernos han implementado un proyecto de modernización compartiendo muchas características con sus predecesores, así como realizando una síntesis con los tres proyectos anteriores. Este aspecto sintético lo interpreta el autor como la producción de un tipo de "fin de la historia".

El texto aquí reseñado parte del supuesto que la modernización en Chile ha sido un continiuum a lo largo de su historia republicana. A pesar de las diferentes vertientes ideológicas y tiempos históricos, el impulso modernizador habría dejado su huella sobre los proyectos nacionales. En este sentido, el autor resalta en qué medida diferentes sectores han buscado insertarse en tales procesos modernizadores, desde disímiles doctrinas e ideologías, impulsadas por las élites, a partir del rol dominante del estado, etc.

La idea de examinar la continuidad antes que la ruptura es, a la vez, la fortaleza como la debilidad del texto que aquí se presenta.

En un sentido, se abandona una mirada parcelada de la historia contemporánea de Chile, lo que permite advertir cómo se han ido traspasando los proyectos modernizadores a pesar de las grandes diferencias de los grupos involucrados. Lo anterior, le permite afirmar al autor que con los gobiernos de la Concertación asistiríamos al "fin de la historia" en la medida en que se habrían cumplido los objetivos propuestos en el pasado. A partir de esta mirada, desde una duración más larga, el autor instala la noción de un "modelo chileno" de modernización que habría logrado solucionar algunos de los problemas más apremiantes del país.

En otro sentido, esta posición tiende a obviar los intereses, propuestas, sensibilidades, etc., de los proyectos implementados durante el siglo XX en Chile, ubicándolos a todos como parte del fenómeno de la modernización. Lo anterior, termina por homogeneizar los proyectos de país, sin poder vislumbrar sus 
contradicciones, oposiciones y enfrentamientos. Finalmente, queda una sensación que, en el fondo, detrás de la noción de modernización, se aludiera ni más ni menos que a la idea del progreso en la historia. ¿Acaso desde comienzos del siglo XX se buscó lo que finalmente los gobiernos de la Concertación llevaron a cabo? De allí que el autor, en un movimiento hegeliano, llegue a afirmar que con los últimos gobiernos se habría entrado en una fase del "fin de la historia": 150 años habían llegado a su feliz término. 